\title{
EFFECTIVENESS OF LIFE SKILLS ON INCREASING SELF-ESTEEM OF HIGH SCHOOL STUDENTS
}

\author{
Dr. Suman Dalal ${ }^{1}$, Ms. Parul ${ }^{2}$, Ms. Ritu ${ }^{3}$ \\ ${ }^{1}$ Associate Professor, Dean Faculty of Education, BPS Institute of Teacher Training \& Research, \\ BPSMV, Khanpur Kalan, Sonepat \\ ${ }^{2,3}$ M.Ed Student
}

Article DOI: https://doi.org/10.36713/epra8727

DOI No: 10.36713/epra8727

\begin{abstract}
The present study was conducted with the purpose to see a study of Effectiveness of life skills on increasing self-esteem of high school students. The present study was conducted to a randomly selected sample of 200 high school student of 6-8th class studying in Government and Private schools of Sonipat deistical in Haryana. Life Skills developed and standardised by M.N.Vranda (2009) \& Self-Esteem developed by Dr.K. G. Agarwal (2015) tool was used for the collection of data in $n$ the present study. The data were analyzed by employing mean, $S D$, ' $t$ '- test \& ' $r$ ' value. The results of the study showed that female students of high schools are found life skills less adjusted than male students of high schools. Govt. school students are found life skills less adjusted than private school students. No significant difference is found in the self-esteem of high school students in relation to their gender and type of school.
\end{abstract}

KEYWORDS: life skill, Self- esteem, Gender, Type of school, high school students.

\section{INTRODUCTION}

Daily life refers to the set of skills that enable us to effectively handle issues commonly encountered in a life skill. Life Skills are psychosocial abilities that enable individuals to translate knowledge and values regarding their concerns into well informed and healthy behaviors. It should therefore be clear that everyone will potentially have a different list of the skills they consider most essential in life, and those that they consider unnecessary. Someone living in a remote rural community might put driving a car high on their list of essential skills. It is also true that different life skills will be more or less relevant at different times your life. For example: Communication skills ,interpersonal skills, Decision-making and problem-solving, Creative thinking, Self-awareness, Assertiveness, self-control, Resilience

\section{SELF-ESTEEM}

Self-esteem is related to personal beliefs about skills, abilities, and social relationships. Self- esteem can refer to the overall self or to specific aspects of the self, such as how people feel about their social standing, racial or ethnic group, physical features, athletic skills, job or school performance. It is the most popular measure of global self-esteem.

\section{REVIEW OF RELATED STUDIES}

Mrs. Sonu Rani, Mr. Neeraj (2020) Conducted a study on "A Study on Life Skill of Senior Secondary Students". Sample of this study was 100 students felled thought random sample method of this study was used descriptive result showed female students of government high school was found less adjusted as compare to male. Government high School Student was found less adjusted as compare to private result indicate that no difference was found of female and male on the bases of life skills. 


\section{JUSTIFICATION OF STUDY}

Education plays an important role towards the overall development of human beings. School education helps in the formation of a sound personality in the child. Today, more and more societal pressures, greater complexity, uncertainty and diversity, rapid changes in the environment an and continued deprivation put Early Childhood stage at the crossroads of their lives facing an uncertain future in facing the responsibilities of adulthood and to enter the world of work. During the $21 \mathrm{st}$ century, life, globally, is undergoing significant transition and change. Among the most affected are the adolescents. Life skills play an essential part of Early Childhood stage which are the future of our country. If students have better life skills and self-esteem they will adjust in a better way and their self-confidence will be higher.

\section{STATEMENT OF THE PROBLEM}

"Effectiveness of life skills on increasing self-esteem of high school students,

\section{Objective of the Study}

1. To study the life skills of high school students.

2. To study the self-esteem of high school students.

3. To compare the Life Skills and Self-esteem female and male high Schools students.

4. To find the relationship between life skills and self-esteem of high school students.

\section{Hypothesis of the study}

1. There exists no significant difference between the Life Skills and Self-esteem of the female and male students of high Schools.

2. There is no significant relationship between the Life Skills and self-esteem of high school students.

\section{Research Methodology:}

In present paper descriptive survey method was used.

\section{Sample of the study}

Sample of the present study is 200 high school students selected on randomly bases including 100 male and 100 female students of $6-8^{\text {th }}$ class.

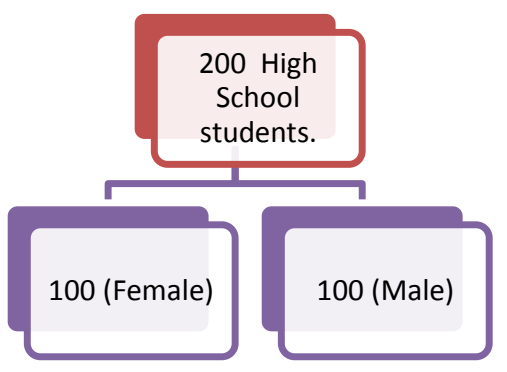

\section{Variable of this study}

Variable i.e. Life Skills, Self-esteem was taken for research work.

Tool used: -

"Life Skills" was developed by M.N.Vranda (2009)

"Self-Esstem" was development by $\mathrm{Dr}$.K. G. Agarwal (2015)

Statistical Techniques Used:

Mean, T-test and ' $r$ ' was used for analysis the data.

\section{RESULT AND DISCUSSION}

Objective-1: To compare the Life Skills and Self-Esteem of Female and Male High school students.

\begin{tabular}{|c|c|c|c|c|c|}
\hline Male & 100 & 31.12 & 22.44 & 0.080 & $\begin{array}{c}\text { Significant at } \\
0.01 \text { level }\end{array}$ \\
\hline
\end{tabular}




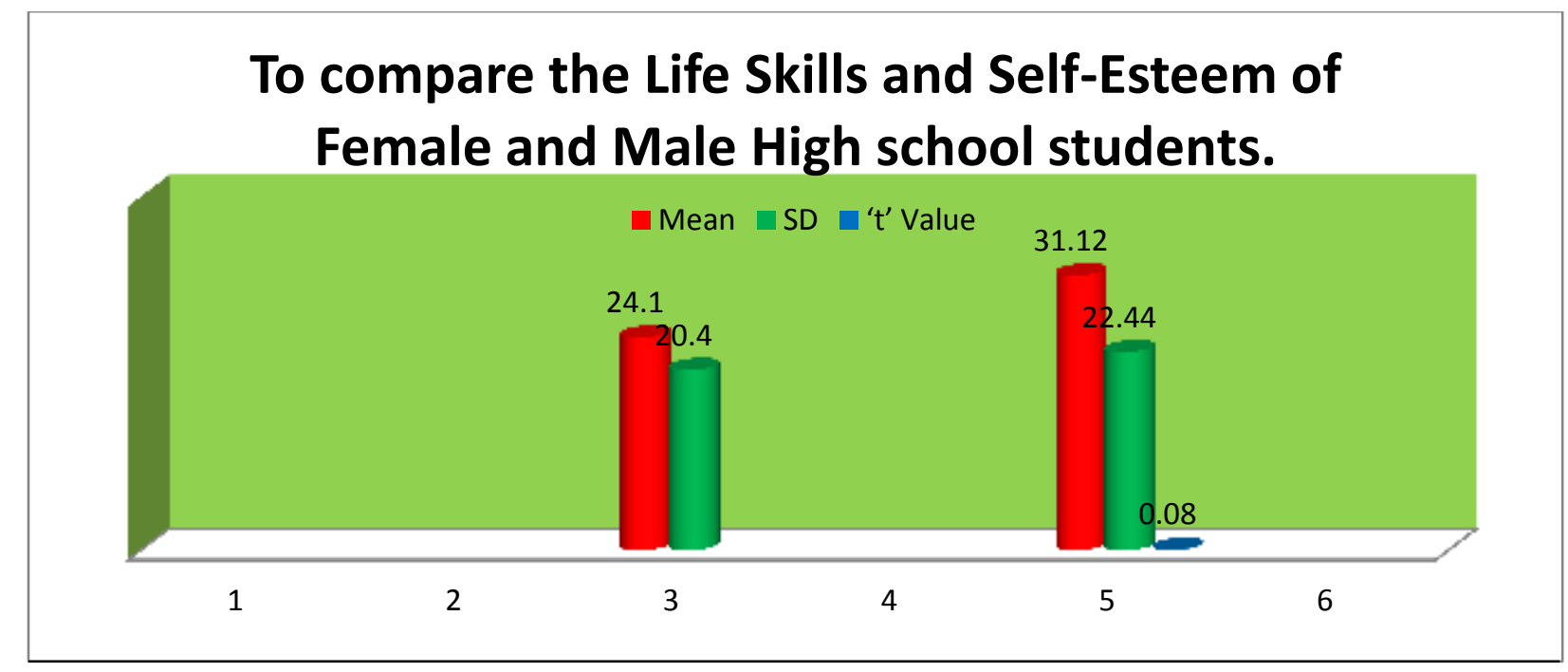

Above table show that, the mean score of life skills of female high school students is 24.10 . The mean score of male high school students is 31.12 . The t- value comes out to be 0.080 which is significant at 0.01 levels. Thus, the null hypothesis there is no significant difference in the life skills of high school students in relation to their gender" is rejected.

2. There is no significant relationship between the Life Skills and self-esteem of high school students.

\begin{tabular}{|c|c|c|c|}
\hline \multicolumn{3}{|c|}{ Table -2 } \\
\hline Group & N & S.D & 'r' Value \\
\hline Male & 100 & 21.54 & 0.072 \\
\hline Female & 100 & 22.70 & \\
\hline
\end{tabular}

The above table shows that the SD of female and male are 22.70 and 21.54 respectively .The calculated value of correlation between life skills and self-esteem of high school students. So the null hypothesis is there is no significant relationship between life skills and self-esteem of high school students.

\section{CONCLUSION}

Life skills are ability for adaptive and positive behavior that individuals to deal effectively with the demands and challenges of everyday life. The findings may useful for the students to understand the basic skills for life and its useful role in education as well as in day to day life. The skills are more helpful for the students to face difficult situation and make them to find a solution. The skills are having more educational value as they develop students' personality and make theme emotionally well fit in nature. Teachers and parents should understand the value of the skills and develop, organize and conduct life skill oriented programs and courses to make the students as intelligent. Thus, the skills are helpful for the college students to promote mental health and competence.

\section{REFERENCES}

1. Rani.Sonu \& Neeraj (2020). International Journal of Scientific Research in Science and Technology,Vol.7(Issue)104-112.

2. Berk, L. E. (2007). Development though the Life Span. Boston: Pearson education.

3. Alka and garishma (2013). "A Study of Attitude of Senior Secondary Teachers about Life Skills

4. Aparna and Raakhee (2011). "life skill education for adolescents: its relevance and importance" GESJ: Education Science and Psychology 2011 No.2(19) ISSN 1512-1801

5. Bailur, K. B.( 2006). Influence of relations of family, peers and pressures of PUC II year students on their adjustment and academic performance. $M$. Sc. Thesis, Univ. Agric. Sci. Hissar 